\title{
O planejamento de sequências didáticas de química fundamentadas no Modelo Topológico de Ensino: potencialidades do Processo EAR (Elaboração, Aplicação e Reelaboração) para a formação inicial de professores
}

\author{
The planning of Chemistry teaching sequences based \\ on the Topological Model of Teaching: potentialities \\ of the EAR (Elaboration, Application and Re-elaboration) \\ process on pre-service teacher education
}

\author{
Amadeu Moura Bego ${ }^{1}$ \\ https://orcid.org/0000-0001-9182-1987 \\ Milena Alves ${ }^{1}$ \\ https://orcid.org/0000-0002-7867-7877 \\ Marcelo Giordan ${ }^{2}$ \\ https:// orcid.org/0000-0002-4646-0139
}

\begin{abstract}
Resumo: Este trabalho objetiva avaliar a influência do processo de Elaboração, Aplicação e Reelaboração (EAR) no desenvolvimento da capacidade de planejamento de sequências didáticas (SDs) de professores de química em formação inicial. Realizou-se uma pesquisa documental qualitativa em duas diferentes versões das SDs de química produzidas pelos professores em formação inicial. A análise dos documentos foi baseada nos princípios do modelo topológico de ensino e em um instrumento-padrão para validação de SDs. Os dados revelaram melhorias significativas nas SDs reelaboradas as quais apresentaram uma abordagem contextualizada e problematizada dos conteúdos, além de um encadeamento mais coeso das atividades didáticas. Conclui-se que o Processo EAR pode se constituir em um importante processo de formação inicial de professores de química, uma vez que fundamenta teórica e metodologicamente o planejamento, além de propiciar ciclos expansivos de qualificação a partir da integração dialética entre teoria e prática e conhecimento específico e pedagógico.
\end{abstract}

Palavras-chave: Formação de professores. Ensino de química. Modelo topológico de ensino. Sequência didática.

\begin{abstract}
This paper aims to evaluate the influence of the Elaboration, Application and Re-elaboration (EAR) process on the development of pre-service chemistry teachers' ability to plan teaching sequences. This study consists of document analysis using two different versions of chemistry teaching sequences (TS) produced by pre-service chemistry teachers. The document analysis was carried out based on the Topological Model of Teaching and on a standard tool for TS validation. The data show significant advances in the redesigned TS, which became more cohesive as regards problem-solving, thus fulfilling the role of a structuring element throughout all teaching activities. This gain can be attributed to the assessment of TS from different perspectives, inserted in this virtuous cycle of the EAR movement, which is fundamental to relate specific contents to pedagogical theories, approximating the theoretical planning and concrete professional practice, as well as developing an investigative attitude about teaching activities.
\end{abstract}

Keywords: Teacher education. Chemistry teaching. Topological model of teaching. Teaching sequence.

\footnotetext{
${ }^{1}$ Universidade Estadual Paulista (UNESP), Instituto de Química, Araraquara, SP, Brasil.

E-mail: amadeu.bego@unesp.br

${ }^{2}$ Universidade de São Paulo (USP), Faculdade de Educação (FE), São Paulo, SP, Brasil.
} 


\section{Introdução}

No âmbito das pesquisas sobre o planejamento de ensino, diversos estudos nacionais e internacionais apontam que, em geral, as práticas de planejamento dos professores se configuram como atividades burocráticas com caráter não consciente e não intencional, além disso os planos de ensino produzidos apresentam objetivos de aprendizagem implícitos e se limitam ao sequenciamento do conteúdo conceitual e às atividades de ensino, tendo-se um único livro didático como referência. Em muitos casos, a atividade docente reduz-se a de administrador de livros didáticos ou de apostilas, fazendo assim com que o professor, renunciando ao ato de planejar consciente e explicitamente seu trabalho em função da realidade de sua escola e de seus alunos, assuma o que o(s) autor(es) do livro ou da apostila considera(m) como mais importante, mais indicado e como necessário ao ensino (BEGO; TERRAZZAN; OLIVEIRA, 2015; MENEGOLLA; SANT’ANNA, 2014; SÁNCHEZ; VALCÁRCEL, 1999).

Entretanto, assumimos que a atividade profissional docente vai além do ato de lecionar, exigindo responsabilidades que não se esgotam no tempo e espaço estrito da sala de aula. Tal circunstância impõe aos docentes dinâmicas relacionadas à organização e gestão do trabalho educativo, que, em um ambiente de educação formal, reclama a imperativa atividade de planejamento. Ademais, consideramos que o planejamento de ensino ressignificado e incorporado à pesquisa é uma das dimensões essenciais para o desencadeamento de inovações educacionais.

Nessa direção, no contexto da área de Educação em Ciências, algumas pesquisas que buscam articular o planejamento de ensino à pesquisa acadêmica têm sido desenvolvidas nos últimos anos. Alguns trabalhos têm como foco o estudo do planejamento de atividades didáticas a partir de diferentes abordagens metodológicas e da análise de seus impactos na aprendizagem de ciências pelos estudantes (SILVA; DEL PINO, 2010), com alguns estudos voltados, inclusive, para o contexto da educação inclusiva (QUEIROZ et al., 2012). Outros trabalhos têm se debruçado sobre a importância do planejamento para a formação tanto inicial como continuada de professores (MACHADO; MARQUES; SILVA, 2016; USTRA; HERNANDES, 2010), incluindo a investigação da capacidade de planejamento de atividades interdisciplinares (WEIGERT; VILLANI; FREITAS, 2005).

Diante desse contexto, advogamos que os professores necessitam ser formados no tocante ao reconhecimento das características e dos elementos do planejamento, bem como de sua importância para sua atividade educativa concreta na escola. Esse aspecto formativo se revela importante, pois, como identificado por Menegolla e Sant'Anna (2014), muitas vezes a repulsa dos professores à atividade de planejar se deve à falta de conhecimento e preparo adequados.

Dentro do campo da Didática, no geral, e da Educação em Ciências, em específico, as abordagens de planejamento baseadas no design de projetos de ensino e aprendizagem avançam em relação à atividade de planejamento aula a aula, uma vez que apresentam-se como uma mudança de concepção e incorporam a perspectiva de sua articulação à pesquisa (BEGO, 2016; GIORDAN, 2008; KNEUBIL; PIETROCOLA, 2017).

Particularmente, defendemos a necessidade de que o planejamento esteja fundamentado em determinadas teorias e abordagens de ensino, tenham fundamentação teórica e metodológica explícita, além de considerar os contextos sociais e institucionais de sua implementação 
(ALVES, 2018; GIORDAN, 2008), a fim de que não sejam pautados meramente por experiências de senso comum de cada professor.

Com efeito, considerando a importância do planejamento de ensino no âmbito da formação professores com vistas à superação das práticas e concepções predominantes, este trabalho tem como foco a formação inicial de professores de química e o processo de validação - elaboração, aplicação e reelaboração - de sequências didáticas (SD) fundamentadas teórica e metodologicamente no Modelo Topológico de Ensino (GIORDAN, 2008). De modo particular, esta investigação tem como objetivo avaliar a influência do Processo EAR no desenvolvimento da capacidade de professores de química em formação inicial para planejarem SD de química fundamentadas teórica e metodologicamente.

\section{A importância do planejamento e o Modelo Topológico de Ensino}

A prática pedagógica, por ser a prática educativa formal e institucionalizada, necessita ser realizada de modo consciente, planejado e explícito a fim de contemplar seu objetivo reclamado socialmente. Decorre dessa premissa o fato de o trabalho docente necessitar ser o resultado de um planejamento com dimensões didática e pedagógica. Nesse sentido, o planejamento de ensino ocupa espaço nevrálgico na ação educativa, visto que é o responsável por definir o trabalho que se intenta realizar, bem como as estratégias para melhor executá-lo e avaliar seu desenvolvimento. Por conseguinte, o planejamento define não só os objetivos pedagógicos, como os princípios norteadores da ação educativa e os mecanismos de avaliação do trabalho a ser realizado (BEGO, 2016; MENEGOLLA; SANT'ANNA, 2014).

Para isso, é preciso superar, de um lado, a visão tecnicista e, de outro, a de total negação do planejamento. A primeira visão enfatiza a importância e necessidade de se planejar de maneira rigorosa, extremamente controlada e fechada, ancorada em uma psicopedagogia de base comportamentalista, na qual o planejamento se limita a definir objetivos, metas, selecionar recursos e estratégias, além de fazer surgir a figura dos profissionais especializados em planejar. Na segunda visão, por meio de críticas ao tecnicismo na educação e ao planejamento como exercício de controle do Estado e de diminuição da autonomia docente, resulta em, paradoxalmente, um enfoque de desconsiderar a importância do planejamento na prática escolar, ou seja, a sumária negação à atividade de planejar (FARIAS et al., 2011).

Defendemos, todavia, que um planejamento sistemático não torna o ensino tecnicista, mas possibilita maior segurança e capacitação aos professores nos momentos necessários de improviso, incertezas e singularidades, inerentes ao ambiente real de sala de aula (ALVES, 2018). Ademais, o planejamento pode fundamentar e qualificar a atuação docente na sala de aula e, integrado à pesquisa, pode desencadear processos de inovação pedagógica (BEGO, 2016).

Em vista disso, o professor necessita conceber o planejamento de ensino como uma ação que envolve deliberações teóricas e metodológicas, bem como uma ação reflexiva e contínua permeada por processos constantes de avaliação. Portanto, planejar é um ato político e ético, uma vez que põe em questão crenças, ideias, valores e opções que alimentam a prática escolar, além de ser também um ato de dimensão técnica, já que exige a definição de meios eficazes para a obtenção de resultados almejados (FARIAS et al., 2011).

No âmbito dessa dimensão da atividade educativa, entendendo que o planejamento de ensino é um importante campo de estudos da Educação em Ciências, bem como um 
importante elemento formativo para integração entre a pesquisa e a prática, vários autores têm proposto a elaboração de modelos para o planejamento e, assim, têm surgido alguns termos, tais como: sequências didáticas, unidades didáticas, unidades de ensino, sequências de ensino e aprendizagem etc.

Giordan, Guimarães e Massi (2012) ao analisarem as tendências de pesquisa sobre SD identificaram que vários trabalhos não trazem referenciais teóricos que norteiam sua elaboração e análise. Os autores destacam, ainda, que não há uma equivalência terminológica para os modelos de planejamento do ensino estruturado, dificultando a busca, o acesso e, consequentemente, a análise de trabalhos na literatura da área. Na direção desse estudo, Alves (2018), em uma revisão sistemática da literatura nacional na área de Educação em Ciências, também identificou a utilização de diversos termos distintos. Segundo a autora, de modo geral, as pesquisas não fazem qualquer tipo de referência sobre a perspectiva teórica ou metodológica que fundamenta os modelos de planejamento adotados, indicando que o uso dos termos vem sendo feito por sua popularização ou a partir das experiências dos professores e/ou pesquisadores. Esse fato indica que as intervenções pedagógicas realizadas em escolas não têm se dado em função de opções teórico-metodológicas conscientes e intencionais.

A despeito desse panorama do cenário brasileiro, Giordan (2008) propõe o Modelo Topológico de Ensino (MTE) para a fundamentação teórica e metodológica do planejamento de SD. Do ponto de vista do planejamento curricular do ensino, as diversas unidades organizadoras do currículo podem, de acordo com o MTE, ser teoricamente pensadas por relações de continência. Da unidade organizadora mais elementar para a mais abrangente, tem-se: atividade de ensino, aula, unidade ou módulo, série, ciclo e vida escolar. O MTE visa dar subsídios para a organização do planejamento de ensino e curricular no que se refere à coerência entre essas diversas unidades organizadoras. Especificamente, o planejamento de SD se situa no terceiro nível de abrangência (GIORDAN, 2008).

O MTE utiliza a Teoria da Ação Mediada (TAM) de James Wertsch (WERTSCH, 1998) como construção teórica que fundamenta o modelo de organização de ensino. A TAM toma, como unidade de análise, a tensão irredutível agentes-agindo-com-ferramentas-culturais de modo a permitir uma análise multifocada e integrada da ação humana e seus motivos, situando-a em seu contexto cultural e institucional.

Essa perspectiva sociocultural situada da ação mediada realça o conceito de ação humana sob a concepção de não isolamento entre sujeito e ambiente, e reconhece seu caráter intrinsecamente mediado. Por isso, entende que o processo de significação do sujeito decorre da internalização de ferramentas emprestadas do grupo social em determinado contexto cultural, ou seja, ferramentas condicionadas institucional e historicamente.

Dessa forma, o MTE estabelece três eixos organizadores do ensino: as atividades estruturadas de ensino, os conteúdos e o tema. As ações realizadas em sala de aula pelos estudantes e pelo professor (agentes) apresentam a especificidade de se darem por meio de atividades estruturadas com determinado propósito educativo. No tocante ao ensino de ciências, o propósito geral das atividades é o de promover a ampliação da visão de mundo dos estudantes em direção às formas de pensamentos da ciência, ou seja, à utilização de conceitos científicos (conteúdos). Os conceitos são as ferramentas culturais, desenvolvidas histórica e socialmente pela ciência, a serem apropriadas pelos estudantes. Por isso, outro elemento importante é a tematização, em função de sua capacidade para aproximar a realidade de partida dos estudantes dos horizontes conceituais científicos. 
O planejamento de SD de acordo com o MTE envolve, assim, a estruturação de ações mediadas por ferramentas culturais específicas de modo a, por meio de atividades de ensino dispostas ao longo do tempo e articuladas entre si, desenvolver narrativas, resolver problemas, interpretar fenômenos e compreender modelos explicativos da ciência. A SD tem sua materialidade na produção de um plano de ensino, que funciona como ferramenta desencadeadora das ações e operações da prática docente em sala de aula (GIORDAN; GUIMARÃES, 2012).

\section{O planejamento de Sequências Didáticas e o conceito de problematização segundo o Modelo Topológico de Ensino}

De acordo com o MTE, algumas propriedades da organização do ensino para o planejamento de SD devem ser observadas, quais sejam, contexto e continuidade, narrativa e historicidade, materialidade e mediação.

Giordan (2008) propõe uma noção ampliada para o conceito de contexto e contextualização que se refere ao entendimento geral entre pessoas que se comunicam. Como decorrência desse entendimento, o contexto apresenta três facetas: situacional, mental e comunicacional.

O que se inicia em um contexto situacional de uma atividade conjunta, mais tarde se torna contexto mental compartilhado de uma experiência, permitindo que professor e alunos continuem o processo de elaboração de ideias apenas por meio da fala, da escrita ou de outras linguagens. Neste movimento da sala de aula, a atividade e o discurso do passado tornam-se contexto mental compartilhado no presente (GIORDAN, 2008, p. 292).

Essa noção ampliada de contexto tem implicações importantes para a organização do ensino, uma vez que não limita o trabalho em sala de aula estritamente ao cotidiano e à concretude do entorno dos alunos. Assim, os alunos podem ampliar seus contextos por meio de temas e conceitos distantes de seu entorno imediato como, por exemplo, temas contemporâneos da ciência discutidos na grande mídia e/ou na internet.

Além dessa ambientação, há a necessidade de um intenso movimento de ampliação das esferas de comunicação e da atividade dos estudantes mediante o esforço verbal do docente para atualizar as experiências anteriores na sala de aula ou no cotidiano. Esse esforço verbal visa produzir o deslocamento comunicacional entre as aulas a fim de abordar assuntos ou eventos distantes no tempo e no espaço e elaborar generalizações abstratas para além de descrições sensitivas da concretude situacional. A continuidade refere-se, justamente, ao desenvolvimento dos contextos no tempo e à relação dos deslocamentos comunicacionais com atividades e falas da sala de aula de acordo com a temática definida (GIORDAN, 2008).

Com efeito, a ação com signos em sala de aula ocorre sob o pano de fundo sócio-institucional e, de acordo com a perspectiva da TAM, o compartilhamento de contextos situacional, mental e comunicacional é a condição determinante para a elaboração de significados, ou seja, para a internalização de ferramentas culturais.

Narrativa e historicidade é outra propriedade importante de organização do ensino, de acordo com o MTE. Para o entendimento adequado do conceito de narrativa na perspectiva 
sociocultural, faz-se necessário compreender o conceito de historicidade da sala de aula, segundo a definição de Giordan (2008). Tal conceito está relacionado à concepção de que os eventos de cada sala de aula são fundados em um sentido histórico próprio, em função de sua situacionalidade. Qualquer situação de sala de aula inelutavelmente se organiza sobre um passado e um futuro da própria sala e sobre as transformações que nela se produzem. Para o autor, a elaboração de conceitos ocorre ao longo do tempo e a construção do pensamento, desse modo, tem caráter processual.

A última propriedade de organização do ensino, de acordo com o MTE, refere-se à mediação e materialidade. A relação humana, de acordo com Vigotski (2009), se dá caracteristicamente pela mediação de ferramentas psicológicas responsáveis por uma função de significação que a diferencia de uma interação imediata natural constituída por reflexos condicionados. Assim, toda ação humana é mediada por ferramentas culturais "que estruturam as ações e as determinam juntamente com os propósitos daqueles que as realizam" (GIORDAN, 2008, p. 302). Outra característica do conceito de mediação no âmbito da TAM, de acordo com Giordan (2008, p. 299), refere-se ao fato "de os meios mediadores (ferramentas culturais) terem sempre um caráter material". A materialidade da ferramenta cultural pode ser reconhecida de modo mais explícito como no caso de utilização de instrumentos físicos (termômetros, lápis, caderno, cronômetro, etc.), mas também é uma propriedade dos dispositivos de pensamento, instrumentos simbólicos, que se utilizam de signos necessariamente veiculados por suportes materiais para estabelecerem a comunicação.

Portanto, o planejamento de uma SD fundamentada teórica e metodologicamente pelo MTE precisa levar em conta as propriedades de organização do ensino determinadas pelo modelo. Nesse sentido, Giordan e Guimarães (2012) propõem uma estrutura de SD formada por elementos organizadores que juntos constituem o plano de ensino do professor. Esse modelo propõe o planejamento em três etapas distintas. Em função dos objetivos deste trabalho e dos limites de espaço, discutimos apenas a Etapa I e o conceito de problematização dentro do MTE.

$\mathrm{Na}$ Etapa I, com o intuito de conferir continuidade e gerar uma narrativa para a SD, os autores destacam a problematização como elemento estruturante que, em função de seu caráter articulador, é responsável por estabelecer um fio de tessitura da SD.

Para além de abordagens de ensino que tomam a problematização apenas como disparadora e motivadora do processo de ensino e aprendizagem, Giordan e Guimarães (2012) concebem que a problematização deve se dar pela formulação de um problema que permeia toda a SD e que articula a dimensão da sociedade - próxima ao contexto situacional dos estudantes e a dimensão da ciência - responsável pela ampliação do contexto comunicacional desses mesmos estudantes mediante a compreensão da realidade a partir das ferramentas culturais da ciência.

Dessa maneira, a problematização a partir de uma temática sociocientífica visa gerar a narrativa tanto em uma escala macro como micro da SD. A primeira escala se desenvolve com a estruturação de uma história capaz de produzir sentido aos conceitos que serão desenvolvidos, enquanto a segunda resulta no estabelecimento de elos entre as atividades e a problematização geral. Como consequência, a dinâmica das atividades, objetivos e conteúdos da SD são escolhidos no sentido de possibilitar uma resposta à problematização.

Portanto, a problematização cumpre o papel de importante elemento integrador da $\mathrm{SD}$ no sentido de fornecer continuidade aos contextos situacionais das diversas aulas que a comporão. Visa gerar uma narrativa através do compartilhamento de contextos - situacionais, 
mentais e comunicacionais - que propiciem a internalização das ferramentas culturais da ciência pelos estudantes.

Como elemento integrador, a capacidade de realizar a problematização de uma SD é vista como um processo condutor da formação do professor, revela faces que tecem relações de proximidade com as etapas de introdução de sua prática em sala de aula e em especial denota a complexidade dos processos formativos nela envolvidos. Por essa razão, defendemos que o processo formativo desenvolvido nesta pesquisa instaura uma prática formativa problematizante que expande o conceito de planejamento para diversas etapas pré- e pós-elaboração dos objetos de ensino - SD e materiais de apoio - e o organiza em torno de um ciclo expansivo de formação capaz de vincular a atuação em sala de aula como um todo estruturado na construção e resolução de problemas que promovam a aprendizagem de conceitos científicos.

\section{Contexto, percursos da pesquisa e procedimentos metodológicos}

A presente pesquisa foi realizada no âmbito do subprojeto Química do Programa Institucional de Bolsa de Iniciação à Docência (PIBID) do Instituto de Química (IQ) da Unesp, câmpus de Araraquara, durante o ano letivo de 2016. Participavam do subprojeto 1 Coordenador de Área (CA), 2 Professores Supervisores (PrS) e 20 Bolsistas de Iniciação à Docência (BID) atuando em 2 unidades escolares parceiras, sendo uma delas escola estadual (EE) e a outra escola estadual técnica (ETEC).

De acordo com a sistemática de funcionamento do subprojeto, os BID se organizavam em duplas ou trios de trabalho sob a supervisão de um dos $\operatorname{PrS}$, atuando em determinado ano do Ensino Médio em uma das escolas parceiras durante todo o ano letivo. Na Figura 1 é apresentada a sequência de ações didáticas e de pesquisa desenvolvidas no ano de 2016.

No tocante à formação dos BID e dos PrS, durante os meses de fevereiro e março de 2016 foram realizadas oficinas de formação, totalizando 24 horas, acerca dos princípios do MTE e de como realizar o planejamento de SD. Os BID e os PrS estudaram e discutiram os textos de Giordan e Guimarães (2012), bem como tiveram acesso a diversas SD produzidas no âmbito do Laboratório de Pesquisa em Ensino de Química e Tecnologias Educativas $(\text { LAPEQ })^{3}$.

\footnotetext{
${ }^{3}$ Nos últimos anos, a equipe do LAPEQ tem elaborado, investigado e publicado uma série de SD de Química. Para mais informações, consultar o website do LAPEQ em: http://www.lapeq.fe.usp.br/.
} 
Bego, A. M.; Alves, M.; Giordan, M.

Figura 1 - Contextos e etapas da pesquisa

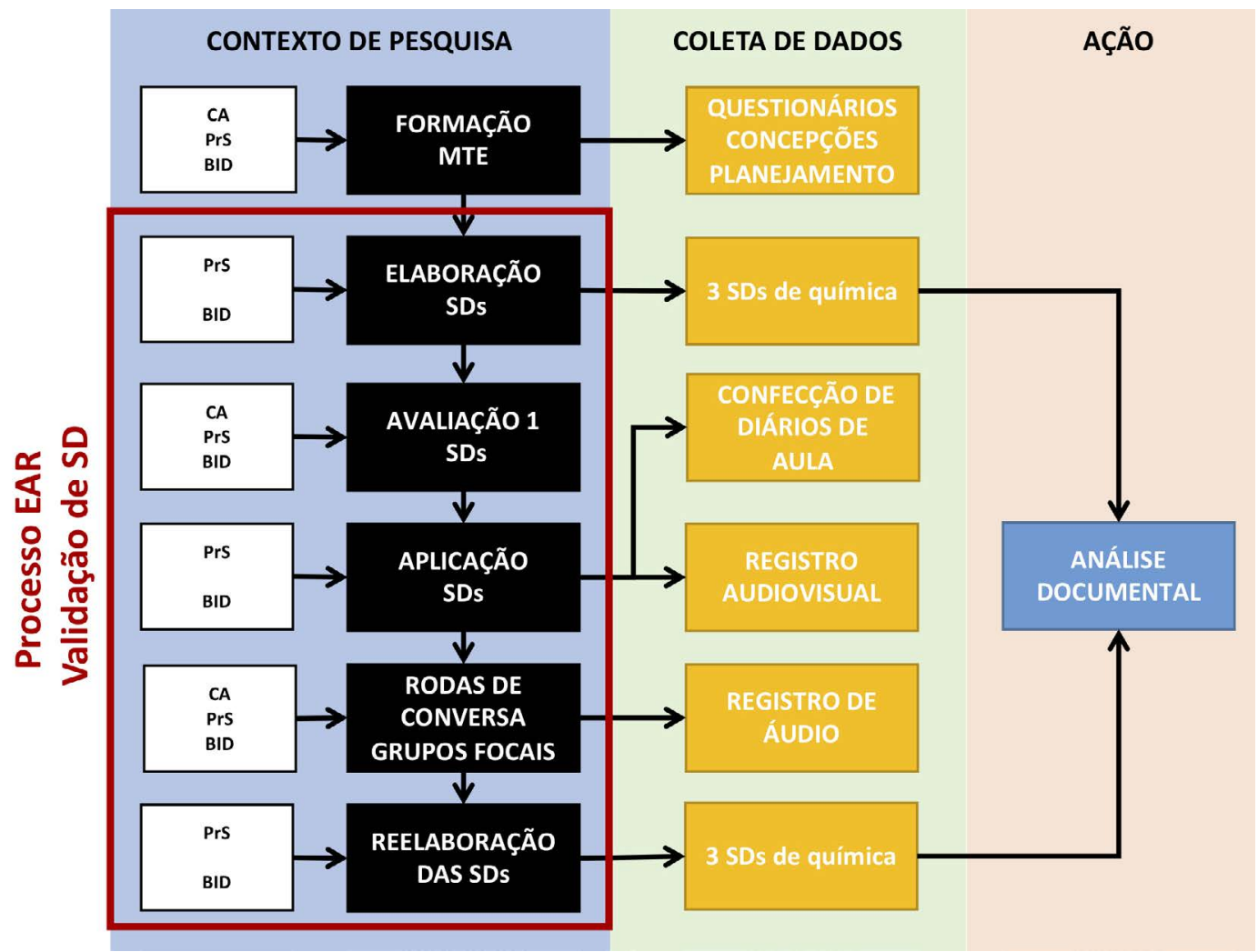

Fonte: Elaborada com base em Sgarbosa (2018).

As demais etapas do processo seguiram os princípios da validação de SD baseadas no MTE, segundo as três fases definidas por Guimarães e Giordan (2013): elaboração, aplicação e reelaboração (EAR). Como pode ser observado na Figura 2, esse processo, estruturado como um sistema de atividades, envolve várias análises sistemáticas em cada uma das fases por meio de investigações e avaliações realizadas em níveis distintos e por diferentes sujeitos.

Entre os meses de abril e julho de 2016, foram planejadas as SD, sendo que cada grupo de trabalho de cada escola parceira elaborou uma SD para um dos três anos do Ensino Médio. Importante ressaltar que o planejamento da SD deveria se pautar nas orientações curriculares oficiais do Estado e no planejamento anual do respectivo PrS.

Ao final da fase de elaboração, as SD foram avaliadas entre pares (BID), pelos PrS e pelo CA, utilizando o instrumento validado por outras pesquisas do LAPEQ (GIORDAN; GUIMARÃES, 2012; GUIMARÃES; GIORDAN, 2013).

Entre os meses de agosto e novembro de 2016, as SD foram aplicadas nos três anos do Ensino Médio de cada escola parceira. Como apontado na Figura 2, a atividade de avaliação perpassa todas as fases do Processo EAR, evitando que a fase de aplicação não se configure 
em mero ativismo acrítico em sala de aula. Nessa perspectiva, durante a fase de aplicação ocorreram atividades de avaliação com duas dimensões diferentes: avaliações individuais por meio da produção de diários de aula (ZABALZA, 2004) e avaliações coletivas nas rodas de conversa semanais do subprojeto (ALBUQUERQUE; GALIAZZI, 2011). Nessa dinâmica, tanto BID como PrS discutiam o andamento da aplicação das SD, os aspectos problemáticos que deveriam ser repensados para a continuidade das aulas, as atividades exitosas e os resultados parciais de aprendizagem dos alunos, sob a mediação do CA à luz dos princípios teóricos e metodológicos do MTE.

Figura 2 - Representação esquemática das fases que compõem cada uma das fases no Processo EAR

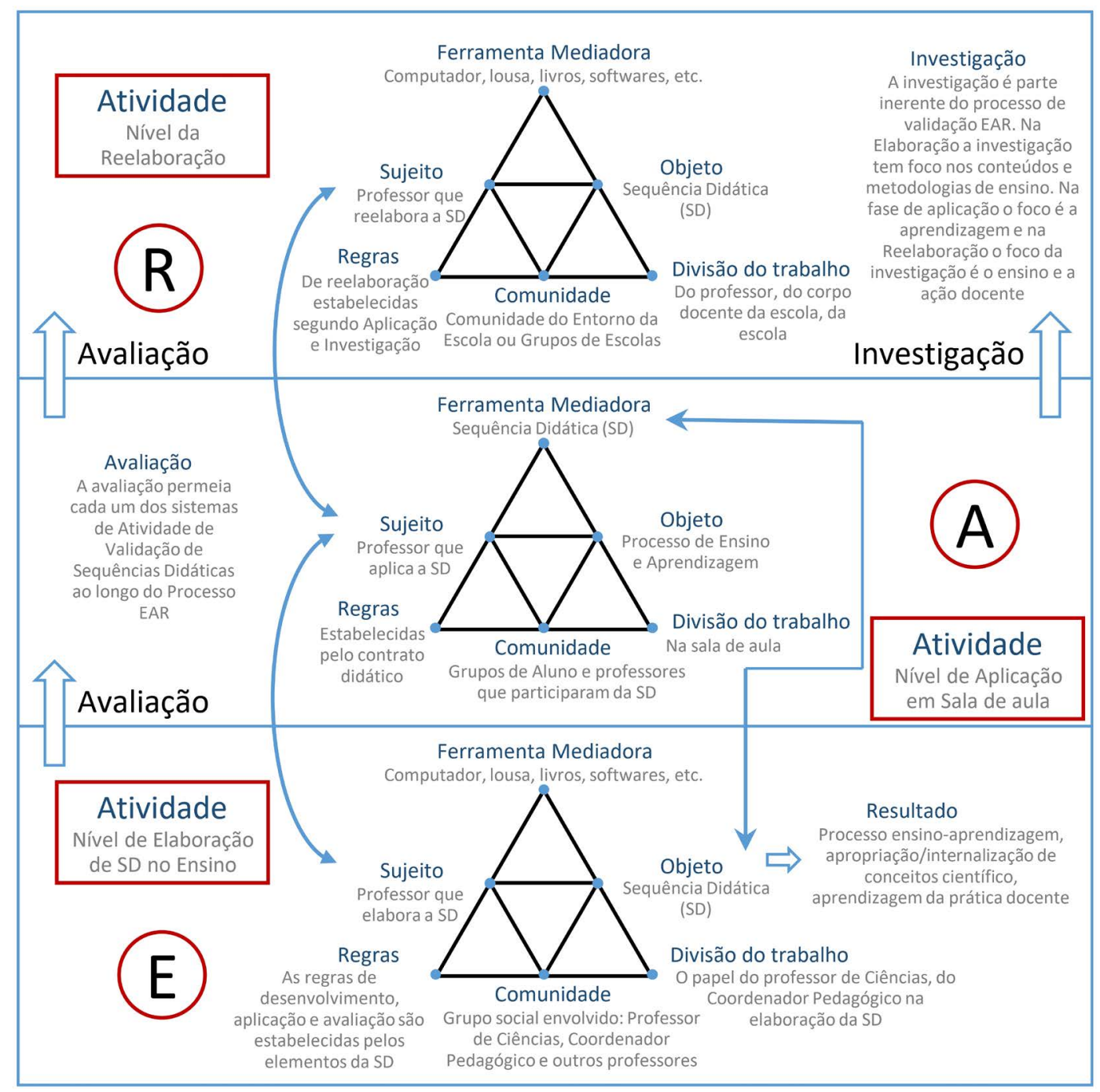

Fonte: Guimarães e Giordan (2013). 
Como o objetivo geral deste trabalho é investigar a incidência do Processo EAR de validação de SD na qualidade do planejamento dos BID no âmbito do subprojeto de Química do Pibid IQ/CAr, realizamos uma pesquisa documental qualitativa (PRIOR, 2003) que utilizou como fonte de dados as SDs produzidas pelos BIDs. A análise das SDs foi baseada nos princípios do MTE e nos fundamentos do instrumento-padrão para validação de SDs proposto por Guimarães e Giordan (2013).

Neste trabalho, analisamos particularmente a dimensão problematização das versões inicial (fase da Elaboração) e final (fase da Reelaboração) das 3 SDs de Química aplicadas na escola parceira ETEC. Esse recorte se deu em função dos limites de espaço e, particularmente, em virtude das características peculiares de se trabalhar com questões sociocientíficas no âmbito do Ensino Médio integrado ao curso técnico (ETEC), acrescido do caráter bastante original das temáticas propostas pelos grupos de BID para o ensino de conteúdos químicos tradicionalmente presentes no currículo deste nível de ensino.

\section{Resultados e discussões}

No quadro 1 são apresentados os resultados da avaliação da versão inicial (fase de Elaboração) e da versão final (fase de Reelaboração) das SDs de Química. Os critérios de avaliação definidos pelo instrumento-padrão são baseados na Escala Likert. A escala do tipo Likert foi desenvolvida por Rensis Likert e consiste em uma escala psicométrica amplamente utilizada para escalar respostas em pesquisas sociais. É de fácil elaboração e aplicação, além de permitir mais homogeneidade e maior confiabilidade na qualidade dos resultados (JAMIESON, 2004; LIKERT, 1932). Vale destacar que o instrumento foi construído e validado por um processo interno do LAPEQ e por sucessivas aplicações em diferentes amostras, de modo a possibilitar que sua utilização vise, justamente, indicar a qualidade de planejamento de uma SD no que tange às suas propriedades internas definidas pelo MTE (GUIMARÃES; GIORDAN, 2013).

Por meio do instrumento, foram atribuídos escores de 1 a 5 para cada quesito avaliativo de cada SD. O escore 1 significa que o avaliador (um dos autores desta pesquisa) discordava totalmente e o escore 5 significa que o avaliador concordava totalmente com a afirmação.

Os critérios de avaliação apresentados no quadro 1 podem ser divididos em dois grupos. Os itens de 1 a 5 (células preenchidas de amarelo) avaliam a contextualização dos conteúdos e os itens 6 a 11 (células preenchidas de verde) avaliam a continuidade e a coesão das atividades. Esses dois grupos de critérios estão relacionados com uma propriedade fundamental do planejamento de SD: a problematização. 
Quadro 1 - Avaliação da versão inicial (fase de Elaboração) e da versão final (fase de Reelaboração) das SD

\begin{tabular}{|c|c|c|c|c|c|c|}
\hline \multirow{2}{*}{ Critérios de Avaliação* } & \multicolumn{2}{|c|}{ SD1 } & \multicolumn{2}{|c|}{ SD2 } & \multicolumn{2}{|c|}{ SD3 } \\
\hline & $\mathrm{E}$ & $\mathrm{R}$ & $\mathrm{E}$ & $\mathrm{R}$ & $\mathrm{E}$ & $\mathrm{R}$ \\
\hline A proposta de ensino apresentada na SD é original & 2 & 3 & 2 & 4 & 3 & 4 \\
\hline $\begin{array}{l}\text { A problematização confronta o senso comum com o conhecimento } \\
\text { científico }\end{array}$ & 2 & 5 & 2 & 5 & 4 & 5 \\
\hline A problematização propõe uma questão desencadeadora & 5 & 5 & 4 & 5 & 5 & 5 \\
\hline $\begin{array}{l}\text { A problematização é relacionada com situações sociais, culturais, políticas } \\
\text { ou do cotidiano }\end{array}$ & 5 & 5 & 4 & 5 & 5 & 5 \\
\hline As atividades são inovadoras & 2 & 3 & 2 & 4 & 3 & 4 \\
\hline $\begin{array}{l}\text { O contexto é adequadamente descrito em seus três aspectos: situacional, } \\
\text { mental e comunicacional }\end{array}$ & 2 & 4 & 2 & 4 & 2 & 4 \\
\hline A problemática articula todos os elementos da SD & 2 & 5 & 1 & 4 & 5 & 5 \\
\hline $\begin{array}{l}\text { A proposta encaminha para a resolução (ou posicionamento crítico) do } \\
\text { problema }\end{array}$ & 3 & 5 & 2 & 4 & 5 & 5 \\
\hline Os conteúdos selecionados são apropriados à problematização & 3 & 5 & 1 & 4 & 4 & 5 \\
\hline $\begin{array}{l}\text { A metodologia de ensino proposta está apropriada para alcançar o } \\
\text { objetivo geral da SD }\end{array}$ & 2 & 5 & 2 & 5 & 5 & 5 \\
\hline Há vínculos entre a dinâmica das atividades e a problematização & 2 & 5 & 1 & 4 & 4 & 5 \\
\hline
\end{tabular}

*Para entendimento aprofundado sobre o significado e as características dos itens de avaliação na perspectiva do MTE, ver Guimarães e Giordan (2013).

Fonte: elaborado pelos autores.

No primeiro grupo de critérios, avaliamos a capacidade dos BID em planejarem SD nas quais os conteúdos fossem adequadamente contextualizados através do uso de questões sociocientíficas que fossem inovadoras e despertassem o interesse dos alunos. A partir dos dados apresentados nos quadros de 2 a 4, observa-se que os BID planejaram SD com temas interessantes e originais (Química sensorial; Fertilizantes sintéticos versus naturais) presentes no contexto social mais amplo, exceto a SD2 que utilizou um tema (água potável e tratamento de água) comumente encontrado em livros didáticos. Dentro das temáticas originais, os BID conseguiram elaborar problematizações relacionadas a situações sociocientíficas com a proposição de questões desencadeadoras de maneira bastante adequada. Inclusive, os títulos das SDs cumprem o papel de refletirem as temáticas e os propósitos de ensino, assim como de serem atrativos e criativos.

Contudo, embora previsto o levantamento de concepções prévias dos estudantes nas primeiras atividades, uma dificuldade apresentada pelos BID, com exceção da SD3, foi planejar problemas que confrontassem o senso comum e o conhecimento científico a partir de temas que apresentassem dimensão sociocientífica indissociável. Como pode ser observado nos quadros de 2 a 4, a problematização da SD 1 foi focada apenas na dimensão científica do problema, enquanto que a SD 2 se centrou basicamente na dimensão social do problema. 
Bego, A. M.; Alves, M.; Giordan, M.

Quadro 2 - Algumas características das duas versões (elaborada e reelaborada) da SD1 aplicada no $1^{\circ}$ ano do EM

\begin{tabular}{|c|c|c|}
\hline Título da SD1 & $\begin{array}{l}\text { Isso não me cheira bem! } \\
\text { (versão inicial) }\end{array}$ & $\begin{array}{l}\text { Isso não me cheira bem! } \\
\text { (versão final)* }\end{array}$ \\
\hline $\begin{array}{l}\text { Trechos de } \\
\text { contextualização }\end{array}$ & $\begin{array}{l}\text { Na imigração japonesa para o Brasil } \\
\text { em 1908, os japoneses trouxeram } \\
\text { consigo seus hábitos que com } \\
\text { o passar dos anos foram sendo } \\
\text { integrados a cultura brasileira. } \\
\text { Restaurantes que oferecem a } \\
\text { culinária japonesa, que possui como } \\
\text { base o pescado, viraram moda e } \\
\text { palavras como sushi e sashimi, } \\
\text { agora, fazem parte do nosso } \\
\text { vocabulário [...] Nos últimos anos } \\
\text { percebemos um grande aumento } \\
\text { do número de estabelecimentos } \\
\text { que oferecem comida japonesa, } \\
\text { inclusive na cidade de Araraquara, } \\
\text { a qual possui } 21 \text { estabelecimentos } \\
\text { registrados, o dobro de uma cidade } \\
\text { com uma quantidade parecida de } \\
\text { habitantes como Rio Claro que } \\
\text { possui apenas } 10 \text { [...] }\end{array}$ & $\begin{array}{l}\text { Na imigração japonesa para o Brasil } \\
\text { em 1908, os japoneses trouxeram } \\
\text { consigo seus hábitos que com o passar } \\
\text { dos anos foram sendo integrados a } \\
\text { cultura brasileira. [...] Nos últimos } \\
\text { anos percebemos um grande aumento } \\
\text { do número de estabelecimentos que } \\
\text { oferecem comida japonesa, inclusive na } \\
\text { cidade de Araraquara, a qual possui } 21 \\
\text { estabelecimentos registrados, o dobro } \\
\text { de uma cidade com uma quantidade } \\
\text { parecida de habitantes como Rio } \\
\text { Claro que possui apenas } 10 \text { [...] Um } \\
\text { problema que aparece com o surgimento destes } \\
\text { estabelecimentos em vários municípios é o } \\
\text { mau cheiro proveniente do pescado quando } \\
\text { ele não é devidamente descartado ou quando } \\
\text { a preservação do local não é feita de forma } \\
\text { eficiente. }\end{array}$ \\
\hline $\begin{array}{l}\text { Questões } \\
\text { desencadeadoras }\end{array}$ & $\begin{array}{l}\text { Como garantir que estes } \\
\text { estabelecimentos não afetem } \\
\text { a população, sendo que o } \\
\text { armazenamento e descarte do } \\
\text { pescado e a manutenção do local } \\
\text { exigem cuidados rigorosos, que } \\
\text { se não forem cumpridos acabam } \\
\text { afetando a qualidade de vida dos } \\
\text { moradores da cidade? }\end{array}$ & $\begin{array}{l}\text { O que diz a legislação sobre o armazenamento } \\
\text { deste pescado? Qual a origem desse odor } \\
\text { proveniente do pescado? Como a química } \\
\text { pode auxiliar numa possivel solução para o } \\
\text { problema? } \\
\text { Como garantir que estes estabelecimentos não } \\
\text { afetem negativamente a população? }\end{array}$ \\
\hline $\begin{array}{l}\text { Objetivo Geral } \\
\text { da SD }\end{array}$ & $\begin{array}{l}\text { A SD tem como objetivo, além de } \\
\text { se ensinar os conceitos de ácido, } \\
\text { base, sais e óxidos, mostrar ao } \\
\text { aluno que a química está presente } \\
\text { no seu dia a dia e que, a partir de } \\
\text { uma visão científica, podem-se } \\
\text { resolver inúmeros problemas de seu } \\
\text { cotidiano }\end{array}$ & $\begin{array}{l}\text { Identificar e classificar as diferentes } \\
\text { funções inorgânicas relacionando-as com as } \\
\text { condicionantes do mau cheiro do pescado nos } \\
\text { restaurantes e as possiveis formas de evitar que } \\
\text { estas atividades prejudiquem a qualidade de } \\
\text { vida da comunidade. }\end{array}$ \\
\hline
\end{tabular}

*Trechos modificados na reelaboração estão grafados em itálico.

Fonte: elaborado pelos autores. 
Quadro 3 - Algumas características das duas versões (elaborada e reelaborada) da SD2 aplicada no $2^{\circ}$ ano do EM

\begin{tabular}{|c|c|c|}
\hline Título da SD2 & $\begin{array}{l}\text { Meu dinheiro por água abaixo: e a } \\
\text { Química com isso? }\end{array}$ & $\begin{array}{l}\text { Meu dinheiro por água abaixo: e a } \\
\text { Química com isso? }\end{array}$ \\
\hline $\begin{array}{l}\text { Trechos de } \\
\text { contextualização }\end{array}$ & $\begin{array}{l}\text { Apesar de } 2 / 3 \text { da superfície terrestre ser } \\
\text { constituída por água, apenas } 1 \% \text { está } \\
\text { disponível para o consumo, sendo } 12 \% \\
\text { oriunda do Brasil. Porém, nosso país } \\
\text { sofre com problemas de desperdício, } \\
\text { causando até mesmo escassez em } \\
\text { algumas regiões [...] Os índices de perdas } \\
\text { de faturamento devido aos desperdícios } \\
\text { geram um menor retorno financeiro, o } \\
\text { que resulta em menor investimento da } \\
\text { rede de saneamento da própria cidade. } \\
\text { Parte desse desperdício está presente no } \\
\text { mau uso doméstico, visto que no Brasil } \\
\text { o consumo médio de água por pessoa } \\
\text { é de } 150-200 \text { litros por dia e segundo a } \\
\text { Pensando nisso, é possível perceber a } \\
\text { importância do tratamento de água e o } \\
\text { prejuízo causado pelo seu desperdício. }\end{array}$ & $\begin{array}{l}\text { Apesar de } 2 / 3 \text { da superfície terrestre ser } \\
\text { constituída por água, apenas } 1 \% \text { está } \\
\text { disponível para o consumo, sendo } 12 \% \\
\text { oriunda do Brasil. No caso de Araraquara } \\
65 \% \text { da água consumida é oriunda do Aquifero } \\
\text { Guarani. O restante é retirado do Ribeirão das } \\
\text { Cruzes, Ribeirão das Anbumas e Córrego do Paiol } \\
{[\text { [..] Uma vez que a água desses rios está cada vez }} \\
\text { mais longe das nascentes e ao decorrer do percurso } \\
\text { ele adentra cada vez mais em áreas urbanas, e } \\
\text { com isso a proteção do rio fica comprometida e } \\
\text { a probabilidade de doencas aumenta, fazendo-se } \\
\text { assim necessário o tratamento de água e também } \\
\text { o uso adequado dos reagentes químicos usados } \\
\text { no tratamento, que é feito em ETAs, onde } \\
\text { procedimentos químicos e físicos são realizados a fim } \\
\text { de garantir que a água torne-se potável. }\end{array}$ \\
\hline $\begin{array}{l}\text { Questões } \\
\text { desencadeadoras }\end{array}$ & $\begin{array}{l}\text { Quais os impactos sociais e econômicos } \\
\text { causados pelo tratamento de água? } \\
\text { Por que a água é tão cara? } \\
\text { Quais substâncias são utilizadas no } \\
\text { tratamento da água? } \\
\text { O que a química tem a ver com esse } \\
\text { valor? }\end{array}$ & $\begin{array}{l}\text { Quais seriam os impactos sociais, econômicos e } \\
\text { ambientais de um tratamento de água feito de } \\
\text { maneira inadequada e qual a importância da } \\
\text { quimica para esse tratamento? } \\
\text { Através de um estudo de caso, a sequência didática } \\
\text { pretende responder ainda as seguintes questôes: Qual } \\
\text { a causa do problema? Em qual etapa do tratamento } \\
\text { de água houve o mau gerenciamento do reagente em } \\
\text { questão? Qual a atitude deve ser tomada para que } \\
\text { o problema seja sanado? Quanto a empresa gastou } \\
\text { devido ao uso incorreto do reagente e como isso pode } \\
\text { impactar no custo da água? }\end{array}$ \\
\hline $\begin{array}{l}\text { Objetivo Geral } \\
\text { da SD }\end{array}$ & $\begin{array}{l}\text { O objetivo dessa SD é que o aluno seja } \\
\text { capaz de reconhecer a importância do } \\
\text { tratamento da água e saiba criticar como } \\
\text { o consumo exagerado proveniente } \\
\text { do uso doméstico leva a problemas } \\
\text { ambientais, econômicos e sociais. Além } \\
\text { disso, espera-se que consiga construir a } \\
\text { relação entre os gastos desnecessários e } \\
\text { os conceitos químicos. }\end{array}$ & $\begin{array}{l}\text { O objetivo dessa sequência didática é que o } \\
\text { aluno seja capaz de justificar a importância da } \\
\text { água potável, dos critérios usados nas etapas do } \\
\text { tratamento de água e como um man gerenciamento } \\
\text { pode levar a problemas ambientais, econômicos e } \\
\text { sociais. }\end{array}$ \\
\hline
\end{tabular}

Fonte: elaborado pelos autores. 
Bego, A. M.; Alves, M.; Giordan, M.

Quadro 4 - Algumas características das duas versões (elaborada e reelaborada) da SD3 aplicada no $3^{\circ}$ ano do EM

\begin{tabular}{|c|c|c|}
\hline Título da SD3 & \multicolumn{2}{|c|}{ Fertilizantes: pode a agricultura destruir nosso planeta? } \\
\hline $\begin{array}{l}\text { Trechos de } \\
\text { contextualização* }\end{array}$ & \multicolumn{2}{|c|}{$\begin{array}{l}\text { Fertilizantes são materiais que contêm nutrientes essenciais para o crescimento } \\
\text { e desenvolvimento das plantas. Os principais nutrientes demandados pelos } \\
\text { vegetais são o nitrogênio, fósforo e potássio, pois são os principais constituintes } \\
\text { de proteínas, ácidos nucleicos e clorofila e essenciais para processos como } \\
\text { transferência de energia, manutenção da pressão interna da planta e ação } \\
\text { enzimática [...] O uso adequado de fertilizantes se tornou ferramenta } \\
\text { indispensável na luta mundial de combate à fome e a subnutrição. Sem eles, } \\
\text { a civilização humana em sua forma atual não existiria. O solo do planeta não } \\
\text { poderia fornecer a todas as } 7 \text { bilhões de pessoas os alimentos que necessitam } \\
\text { [...] O nitrogênio é constituinte principal de proteínas. Entretanto, a agricultura } \\
\text { requer mais nitrogênio do que a natureza consegue fornecer. Desta forma, a } \\
\text { química desempenha papel fundamental, porque a síntese de fertilizantes a } \\
\text { base de nitrogênio supre a demanda desse elemento pela agricultura [...] O uso } \\
\text { excessivo de fertilizantes polui rios, lagos e lençóis freáticos, além de contribuir } \\
\text { para o aquecimento global... }\end{array}$} \\
\hline $\begin{array}{l}\text { Questões } \\
\text { desencadeadoras }\end{array}$ & $\begin{array}{l}\text { Como alimentar a } \\
\text { população mundial } \\
\text { sem a otimização de } \\
\text { produção agrícola? } \\
\text { Como fornecer } \\
\text { nutrientes essenciais } \\
\text { a todos os habitantes } \\
\text { do planeta? Como } \\
\text { aumentar a produção } \\
\text { de fertilizantes, de } \\
\text { modo a suprir a } \\
\text { demanda mundial? } \\
\text { De que maneira o } \\
\text { uso excessivo desses } \\
\text { compostos influencia } \\
\text { no equilíbrio natural } \\
\text { do planeta? Como } \\
\text { substituir esses } \\
\text { materiais sintéticos } \\
\text { de modo a suprir a } \\
\text { demanda mundial por } \\
\text { alimentos? }\end{array}$ & $\begin{array}{l}\text { Como alimentar a população mundial sem a } \\
\text { otimização de produção agrícola? Como fornecer } \\
\text { nutrientes essenciais a todos os habitantes do planeta? } \\
\text { Como aumentar a produção de fertilizantes, de modo } \\
\text { a suprir a demanda mundial? } \\
\text { De que maneira o uso excessivo desses compostos influencia no } \\
\text { equilíbrio natural do solo do planeta? Como substituir esses } \\
\text { materiais sintéticos de modo a suprir a demanda mundial por } \\
\text { alimentos? A quantidade de fertilizantes utilizada nos dias } \\
\text { atuais é realmente necessária para suprir a demanda mundial } \\
\text { por alimentos? }\end{array}$ \\
\hline $\begin{array}{l}\text { Objetivo Geral da } \\
\text { SD* }\end{array}$ & \multicolumn{2}{|c|}{$\begin{array}{l}\text { Essa SD tem como objetivo geral que o aluno seja capaz de criticar o uso } \\
\text { de fertilizantes no cenário agrícola mundial, justificando a influência do uso } \\
\text { excessivo de fertilizantes no equilíbrio químico natural. }\end{array}$} \\
\hline
\end{tabular}

*Após o Processo EAR os BID julgaram que não houve necessidade de modificação do item da versão reelaborada.

Fonte: elaborado pelos autores. 
Ainda em relação ao primeiro grupo de critérios, é interessante notar nos dados do quadro 1 que, apesar dos temas originais utilizados nas SD, as propostas de ensino não se caracterizam totalmente como inovadoras. Nas três SD, por exemplo, identificou-se que a maioria das atividades foi planejada com a abordagem comunicativa não interativa de autoridade (MORTIMER; SCOTT, 2002), com o professor ocupando o papel centralizado de transmissor dos conteúdos. As aulas majoritariamente foram planejadas para a utilização de lousa e caneta como materiais de apoio, com os alunos dispostos na sala com as carteiras enfileiradas. Apenas em cinco atividades a abordagem planejada era do tipo interativa e dialógica, com propósitos de apresentação da problematização, discussão de conteúdo, orientação de estudo de casos e retomada da problematização da SD.

Com efeito, é interessante observar que, mesmo tendo participado das discussões e estudos acerca do MTE e elaborado a problematização a partir de temas originais, os BID tenderam a estruturar atividades de ensino de maneira mais tradicional, principalmente nas aulas destinadas ao ensino do conteúdo químico. Esses dados vão ao encontro das afirmações de Tardif (2012), segundo as quais, em geral, futuros professores, independente do nível de atuação, passam longos anos de seu percurso educacional frequentando o que irá ser seu futuro local de trabalho. Esse fato resulta em uma forte imersão formadora que leva esses indivíduos a adquirirem crenças e certezas sobre o ofício docente. Por isso, através da experiência escolar pré-profissional ocorre a incorporação acrítica e inconsciente de práticas decorrentes da interação social com antigos professores e são gerados saberes que resistem ao longo do tempo e influenciam diretamente a atuação em sala de aula desses futuros professores.

No segundo grupo de critérios, avaliamos a capacidade dos BID em planejarem SD com as atividades estruturadas de forma coesa, de modo a gerar uma história que desse sentido aos conceitos científicos a serem aprendidos pelos alunos. Por isso, as atividades estruturadas que iriam compor uma aula ou um módulo não deveriam ser concebidas, na perspectiva do MTE, como unidades isoladas ou meramente justapostas.

Com exceção da SD3, os BID tiveram grande dificuldade para estruturar e articular o problema proposto com todos os elementos da SD. No caso da SD1, os conteúdos e objetivos das aulas se restringiram à questão de identificação da substância malcheirosa do pescado e ao reconhecimento de seu caráter básico, a qual justificaria sua neutralização por ácidos, a exemplo do ácido cítrico presente no limão. Ao longo das dez aulas da SD não foram abordados outros fatores que fornecessem elementos suficientes para a adequada compreensão e discussão da ampla problemática pretendida, como, por exemplo, a legislação que rege os estabelecimentos comerciais desse tipo de atividade econômica e os impactos dessa prática na comunidade local. Outro aspecto se refere a pequenas rupturas na narrativa em função da quebra dos contextos situacionais e mentais ao longo das aulas. Em alguns pontos, ficou patente que os conteúdos químicos por si próprios assumiam o principal propósito das aulas, sem relação direta com o problema, o que implicou na ausência de elos consistentes entre as atividades e entre sua dinâmica e a problematização geral.

Na primeira versão da SD 2, como pode ser observado no Quadro 3, para a discussão e a resolução do problema apresentado, identificou-se que não havia obrigatoriedade da utilização dos conhecimentos químicos de estequiometria. Logo, não havia relação adequada entre a importância do tratamento de água, os conhecimentos químicos envolvidos e a problemática do desperdício de água potável. Assim, podemos afirmar que não houve um encaixe adequado 
entre a dimensão social e a dimensão científica do problema proposto, que possibilitasse gerar uma narrativa consistente ao longo das atividades da SD.

Esses problemas não são identificados na SD3. Como pode ser observado no Quadro 4, a problematização, para além de disparadora e motivadora inicial, perpassa e articula todas as atividades e a proposta encaminha para o posicionamento crítico sobre a questão das vantagens e desvantagens da utilização de fertilizantes sintéticos, com a utilização dos conceitos acerca das importantes relações de equilíbrio químico do solo envolvendo o nitrogênio.

Como descrito na seção anterior, após a avaliação das primeiras versões das SD, e antes de sua aplicação nas salas de aulas, os BID fizeram as correções necessárias. Posteriormente, durante as aplicações das SD houve a realização semanal das rodas de conversa e da produção individual dos diários de aula. Após esse processo crítico-reflexivo, os grupos passaram para a fase de reelaboração das respectivas SD.

A partir dos dados anteriormente apresentados no quadro 1, em relação ao primeiro grupo de critérios, é possível notar uma considerável melhoria da qualidade das SD reelaboradas. Isso significa que os conteúdos abordados nas SD estão melhor contextualizados a partir de questões sociocientíficas.

No caso da SD1, conforme dados do quadro 2, percebe-se a modificação da questão desencadeadora e a introdução de subproblemas compondo o problema inicial. A inserção das questões acerca da origem do odor do pescado e de como garantir que os estabelecimentos comerciais não afetem a população, incluindo a especificação dessas questões na contextualização inicial, foram fundamentais para a articulação entre o senso comum (o que os estudantes pensam sobre essas questões?) e o conhecimento científico a ser desenvolvido na SD. Outra modificação importante se referiu à formulação do objetivo geral da SD, que, segundo o MTE, cumpre o papel de promover uma tensão dialética entre contexto, problematização da SD, propósitos de ensino do professor e os resultados de aprendizagem almejados. Enquanto na primeira versão o objetivo geral foi escrito na perspectiva do ensino (o que os BID pretendiam fazer como professores), na segunda versão o objetivo foi escrito na perspectiva da aprendizagem (quais aprendizagens esperavam dos estudantes), além de estar melhor delimitado e mais articulado com a problemática da SD.

O mesmo pode ser observado para a SD2, em que os BID decidiram reformular totalmente a problematização. Houve a mudança do enfoque das questões desencadeadoras para a importância do tratamento da água nas estações de tratamento e não para a temática do desperdício. Percebemos que ocorreu uma melhor articulação entre os conteúdos químicos (relações estequiométricas envolvidas no tratamento de água) e os impactos socioambientais do tratamento de água. Notamos inclusive na versão final da SD2 o confronto mais explícito entre o senso comum e o conhecimento científico, a partir da opção de utilização de um Estudo de Caso investigativo, de acordo com a proposta de Sá, Francisco e Queiroz (2007).

No tocante à abordagem comunicativa utilizada em todas as SDs, ao contrário do observado para a problematização, identificou-se que houve apenas alterações pontuais com a inserção de algumas atividades interativas e dialógicas. Entretanto, a maioria das atividades ainda foi planejada com abordagem comunicativa não interativa e de autoridade, com a utilização de lousa e caneta como materiais de apoio e os alunos dispostos na sala com as carteiras enfileiradas.

Esse é um dos aspectos em que, apesar do Processo EAR, as concepções acerca de como estruturar as sequências das aulas e definir as abordagens comunicativas não sofreram 
modificações significativas. Não se identificou uma fundamentação explícita que orientou de modo consistente a estruturação dos tipos de abordagem comunicativa ao longo do desenvolvimento do problema ao longo das aulas, como, por exemplo, o padrão rítmico proposto por Mortimer e Scott (2002) (que havia sido detidamente discutido nas oficinas de formação dos BID). Esse padrão indica a necessidade de se iniciar uma SD com a abordagem interativa e dialógica para discutir as ideias relevantes; depois a abordagem interativa de autoridade para trabalhar aspectos do conteúdo científico; e a finalização com abordagem não interativa para rever o progresso da "estória científica" e manter a narrativa de ensino no plano da sala de aula. Vale sublinhar que, neste texto, utilizamos o termo estória científica de acordo com a proposta de Mortimer e Scott (2002), segundo a qual o professor irá estabelecer com os estudantes uma narrativa no plano social da sala ao longo das aulas com a finalidade engajar os estudantes, intelectual e emocionalmente, ajudando-os a seguir seu desenvolvimento, a entender suas relações com o currículo de ciências como um todo e a dar significado aos conceitos da ciência. Nesse sentido, o termo se refere à história que se conta e se estabelece na própria historicidade da sala de aula, o que é diferente da acepção comumente dada à utilização da história da ciência em sala de aula (GIORDAN, 2008).

Os BID parecem manter a concepção de que as atividades dialógicas são destinadas essencialmente para apresentar ou retomar a problematização e os conteúdos químicos devam ser necessariamente apresentados com atividades não interativas em que o professor assume o papel de transmissor. Esse fato, assim como discutido anteriormente, mostra a resistência das concepções de ensino tradicionais dos professores em função da ampla e profunda experiência pré-profissional no ambiente de sala de aula (TARDIF, 2012). Esse é um aspecto relevante a ser devidamente circunstanciado, investigado e trabalhado na continuidade do projeto.

A despeito dessa constatação sobre a resistência de os bolsistas manterem o planejamento de atividades não inovadoras e abordagens comunicativas não dialógicas, no segundo grupo de critérios, como apresentado anteriormente no quadro 1, foi expressiva a melhoria na qualidade das SD reelaboradas. De maneira geral, as atividades foram estruturadas de forma mais coesa e melhor articuladas com a problematização. No caso da SD1, os BID inseriram mais duas aulas e redistribuíram os conteúdos de modo mais adequado. Como a problematização incluiu, além do mau cheiro do pescado, a discussão sobre a questão da importância do correto armazenamento do pescado nos estabelecimentos comerciais para evitar problemas para a comunidade, os BID inseriram também conteúdos sobre as regras e a legislação acerca do armazenamento de pescado e sua relação com o processo de decomposição do óxido presente no pescado responsável pela formação da substância malcheirosa. Além disso, pela análise das descrições dos contextos situacionais e mentais das atividades e dos propósitos das aulas, notou-se claramente a melhor articulação entre todos os elementos da SD, bem como vínculos mais consistentes entre a dinâmica das atividades e a problematização.

O mesmo ocorreu com a versão final da SD2. Com a total reformulação da problematização, houve o adequado encaixe entre a dimensão da sociedade e da ciência, uma vez que nessa nova versão os estudantes necessariamente precisariam se apropriar das ferramentas culturais da química para entender e resolver o problema proposto. Sem a realização correta dos cálculos estequiométricos, os estudantes não consegueriam descobrir os problemas de saúde que o uso incorreto de reagentes químicos (reagentes em excesso) no tratamento de água pode provocar na população, bem como os impactos econômicos para o município. Pela análise dos 
contextos situacionais e mentais ao longo das atividades, fica muito mais clara a narrativa que é gerada ao longo da SD.

Consideramos que as melhorias identificadas nas versões reelaboradas das SD se devem ao contato pródigo e dialético dos BID com a dimensão prática da profissão durante a aplicação das SD associado à atividade de constante avaliação que perpassa todas as fases do Processo EAR. Além disso, outro fator de destaque se refere à interação frutífera e cooperativa entre pares, $\operatorname{PrS}$ e CA.

Em relação ao primeiro fator, destacamos que o planejamento de SD fundamentadas teórica e metodologicamente é fundamental para o movimento de reflexão sobre a própria prática, pois as SD se constituem em ferramentas culturais mediadoras que os professores utilizam para sua análise crítica. Planejar uma SD de acordo com o MTE implica em fazer uma série de opções e em explicitar uma série de intenções de ensino (objetivos, propósitos, abordagem comunicativa, avaliação etc.). Por isso, os professores em formação inicial, cuja experiência didática ainda é bastante incipiente, conseguem ter parâmetros balizadores para analisar a distância entre o teórico planejado e o efetivamente realizado, verificando as inconsistências, os erros, as potencialidades e os acertos. Durante esse processo dialético, os BID foram enxergando a importância de se resgatar os contextos mentais ao longo das aulas de modo a gerar a narrativa que permitisse a resolução ou o posicionamento crítico sobre o problema colocado, além de possibilitar a apropriação das ferramentas culturais da química. Por isso, os conceitos abstratos e teóricos sobre o MTE começaram a fazer sentido para muitos dos BID durante a prática reflexiva, promovendo, de fato, a apropriação dos mesmos.

Já em relação ao segundo aspecto, podemos afirmar que todos esses movimentos reflexivos foram potencializados no âmbito do PIBID, justamente por causa de sua estrutura de funcionamento na qual os BID atuam em grupos de trabalho colaborativos, sob supervisão direta de professores em exercício da rede básica ( $\mathrm{PrS}$ ) e de um professor formador da universidade (CA) (BEGO, 2017).

\section{Considerações finais}

O presente trabalho empírico objetivava avaliar a influência do Processo EAR no desenvolvimento da capacidade de professores de química em formação inicial para planejarem SD de química fundamentadas teórica e metodologicamente. É possível afirmar que houve expressiva melhora na capacidade de planejamento dos BID no que tange à proposição de SD de química com uma abordagem contextualizada e problematizada dos conteúdos, bem como com encadeamento coeso de atividades didáticas a partir da delimitação de propósitos de ensino em articulação com objetivos de aprendizagem. Identificamos avanços significativos no planejamento das SD reelaboradas, as quais se tornaram mais coesas com a problematização cumprindo o papel de elemento estruturante das atividades didáticas.

Cabe sublinhar que, em que pese as potencialidades do Processo EAR e do intenso movimento de reflexão sobre a própria prática, do ponto de vista do planejamento, algumas concepções tradicionais de ensino dos BID são bastante resistentes e parecem não sofrer modificações expressivas, como aquelas realizadas às formas de organizar a interação professor-aluno. Esse fato sugere investigações posteriores mais específicas e, até mesmo, o 
acompanhamento dos resultados da participação de alguns BID em ciclos expansivos reiterados de processos EAR.

Nesse sentido, porém, os dados apontam que o Processo EAR de validação de SD pode se constituir em um importante processo para a formação inicial de professores de química a fim de superação das visões simplistas acerca das características e da importância do planejamento, uma vez que, de um lado, fundamenta teórica e metodologicamente e, de outro, sistematiza as etapas de intervenções educativas no ambiente escolar. Além disso, para além das práticas tecnicistas, no âmbito do Processo EAR, fomenta-se a dimensão autoral do planejamento de ensino, em que os professores são instados a fazer opções embasadas teoricamente, bem como refletir e explicitar suas intenções de ensino em função de seu contexto concreto de atuação. Outro aspecto do processo se refere à articulação do planejamento com a atividade de pesquisa sobre a própria prática pautada na constante dialética entre a prática profissional e a formação teórica, na qual teoria e prática são articuladas de forma integrada, indissociável e complementar.

\section{Agradecimentos}

Os autores agradecem ao Ministério da Ciência, Tecnologia e Inovação e ao Conselho Nacional de Desenvolvimento Científico e Tecnológico (CNPq) pelo financiamento da pesquisa (425810/2016-0), também agradecem à Coordenação de Aperfeiçoamento de Pessoal de Nível Superior (CAPES) pelo financiamento do projeto institucional da Unesp "O processo de formação de licenciandos: ações conjuntas da Universidade Pública e da Escola de Educação Básica" que integrou o Programa Institucional de Bolsa de Iniciação à Docência - PIBID/CAPES (Edital CAPES/DEB n. 61/2013).

\section{Referências}

ALBUQUERQUE, F.; GALIAZZI, M. C. A formação do professor em rodas de formação. Revista Brasileira de Estudos Pedagógicos, Brasília, v. 92, n. 231, p. 386-398, 2011.

\section{ALVES, M. Características, elementos e importância do planejamento didático-} pedagógico: uma revisão de termos e conceitos na área de ensino de ciências. 2018. $130 \mathrm{f}$. Dissertação (Mestrado em Química) - Instituto de Química, Universidade Estadual Paulista, Araraquara, 2018.

BEGO, A. M. A implementação de unidades didáticas multiestratégicas na formação inicial de professores de química. Textos FCC, São Paulo, v. 50, p. 55-72, 2016. Disponível em: http://publicacoes.fcc.org.br/ojs/index.php/textosfcc/article/view/4316/3233. Acesso em: 7 ago. 2019

BEGO, A. M. O Pibid como novo paradigma de formação de professores: vivências, saberes e práticas formativas inovadoras do subprojeto de química da Unesp. Crítica Educativa, Sorocaba, v. 3, n. 2, p. 709-726, 2017. DOI: https://doi.org/10.22476/revcted.v3i2.199. 
BEGO, A. M.; TERRAZZAN, E. A.; OLIVEIRA, L. A. A. Trabalho docente e sistemas apostilados de ensino: crítica à luz da teoria habermasiana. Comunicações, Piracicaba, ano 22, n. 2, p. 101-110, 2015. DOI: https://doi.org/10.15600/2238-121X/comunicacoes. v22n2p101-110

FARIAS, I. M. S.; SALES, J. O. C. B.; BRAGA, M. M. S. C.; FRANÇA, M. S. L. M. Didática e docência: aprendendo a profissão. 3. ed. Brasília: Liber Livro, 2011.

GIORDAN, M. Computadores e linguagens nas aulas de ciências. Ijuí: Ed. Unijuí, 2008.

GIORDAN, M.; GUIMARÃES, Y. A. F. Estudo dirigido de iniciação à sequência didática. São Paulo: Universidade de São Paulo, 2012. (Material de disciplina de curso de especialização em ensino de ciências oferecido pelos autores à Rede São Paulo de Formação Docente - REDEFOR).

GIORDAN, M.; GUIMARÃES, Y.; MASSI, L. Uma análise das abordagens investigativas de trabalhos sobre sequências didáticas: tendências no ensino de ciências. In: ENCONTRO NACIONAL DE PESQUISA EM EDUCAÇÃO EM CIÊNCIAS, 8. e CONGRESSO IBEROAMERICANO DE EDUCAÇÃO EM CIÊNCIAS, 1., 2012, Campinas. Atas [...]. Rio de Janeiro: ABRAPEC, 2012, p. 1-12.

GUIMARÃES, Y.; GIORDAN, M. Elementos para validação de sequências didáticas. In: ENCONTRO NACIONAL DE PESQUISA EM EDUCAÇÃO EM CIÊNCIAS, 9., 2013, Águas de Lindóia. Anais [...]. São Paulo: ABRAPEC, 2013, p. 1-8.

JAMIESON, S. Likert scales: how to (ab)use them. Medical Education, Chichester, v. 38, n. 12, p. 1217-1218, 2004.

KNEUBIL, F. B.; PIETROCOLA, M. A pesquisa baseada em design: visão geral e contribuições para o ensino de ciências. Investigações em Ensino de Ciências, Porto Alegre, v. 22, n. 2, p. 1-16, 2017.

LIKERT, R. A technique for the measurement of attitudes. Archives of Psychology, New York, n. 140, p. 1-55, 1932.

MACHADO, A. R.; MARQUES, C. A.; SILVA, R. M. G. Sentidos e significados de problema e problematização em um processo de (re)planejamento coletivo de uma situação de estudo. Ciência \& Educação, Bauru, v. 22, n. 1, p. 23-42, 2016. DOI: https://doi. org/10.1590/1516-731320160010003.

MENEGOLLA, M.; SANT’ANNA, I. M. Por que planejar? Como planejar? Currículoárea-aula. 13. ed. Petrópolis: Vozes, 2014.

MORTIMER, E. F.; SCOTT, P. Atividade discursiva nas salas de aula: uma ferramenta sociocultural para analisar e planejar o ensino. Investigações em Ensino de Ciências, Porto Alegre, v. 7, n. 3, p. 283-306, 2002.

PRIOR, L. Using documents in social research. New York: Sage, 2003. 
QUEIROZ, T. G. B.; SILVA, D. F.; MACEDO, K. G.; BENITE, A. M. C. Estudo de planejamento e design de um módulo instrucional sobre o sistema respiratório: o ensino de ciências para surdos. Ciência \& Educação, Bauru, v. 18, n. 4, p. 913-930, 2012. DOI: https://doi.org/10.1590/S1516-73132012000400011.

SÁ, L. P.; FRANCISCO, C. A.; QUEIROZ, S. L. Estudos de caso em química. Química Nova, São Paulo, v. 30, n. 3, p. 731-739, 2007. DOI: https://doi.org/10.1590/S010040422007000300039.

SÁNCHEZ, G. B.; VALCÁRCEL, M. V. Science teachers' views and practices in planning for teaching. Journal of Research in Science Teaching, Hoboken, v. 36, n. 4, p. 493-513, 1999.

SGARBOSA, E. C. A comunicação multimodal e o planejamento de ensino na formação inicial de professores de química. 2018. 238 f. Dissertação (Mestrado em Ensino de Ciências) - Faculdade de Educação, Instituto de Física, Instituto de Química e Instituto de Biociências, Universidade de São Paulo, São Paulo, 2018.

SILVA, D. R.; DEL PINO, J. Aulas de ciências na oitava série do ensino fundamental: uma proposta de projeto curricular como processo em construção. Ciência \& Educação, Bauru, v. 16, n. 2, p. 447-464, 2010. DOI: https://doi.org/10.1590/S1516-73132010000200012.

TARDIF, M. Saberes docentes e formação profissional. 13. ed. Petrópolis: Vozes, 2012.

USTRA, S. R. V.; HERNANDES, C. L. Enfrentamento de problemas conceituais e de planejamento ao final da formação inicial. Ciência \& Educação, Bauru, v. 16, n. 3, p. 723-733, 2010. https://doi.org/10.1590/S1516-73132010000300015.

VIGOTSKI, L. S. A construção do pensamento e da linguagem. 2. ed. São Paulo: Martins Fontes, 2009.

WEIGERT, C.; VILLANI, A.; FREITAS, D. A interdisciplinaridade e o trabalho coletivo: análise de um planejamento interdisciplinar. Ciência \& Educação, Bauru, v. 11, n. 1, p. 145-164, 2005. https://doi.org/10.1590/S1516-73132005000100012.

WERTSCH, J. V. Mind as action. New York: Oxford Univ. Press, 1998.

ZABALZA, M. A. Diários de aula: um instrumento de pesquisa e desenvolvimento profissional. Porto Alegre: Artmed, 2004.

Submetido em 07/09/2018. Aceito em 27/03/2019

Contato: UNESP, Instituto de Química, Departamento de Química Geral e Inorgânica, Rua Prof. Francisco Degni, 55, Jardim Quitandinha, Araraquara, SP, 14800-900, Brasil. 
